\title{
Home Physical Activity Programs for Children and Adolescents as a Healthy Strategy During Social Isolation Caused by COVID-19: viewpoint
}

Rafaela Catherine da Silva Cunha de Medeiros, ${ }^{1,2}{ }^{\circledR}$ Isis Kelly dos Santos, ${ }^{1}{ }^{\circledR}$ Jason Azevedo de Medeiros, ${ }^{10}$ Ricardo Ney Cobucci, ${ }^{\circledR}$ Tatiane Andreza Lima da Silva, ${ }^{1 \oplus}$ Juliany de Souza Araujo, ${ }^{\circledR}$ Phelipe Wilde de Alcântara Varela, ${ }^{3}{ }^{\circledR}$ Breno Guilherme de Araújo Tinoco Cabral, ${ }^{3}$ Paulo Moreira Silva Dantas ${ }^{1,3}$ (1)

Postgraduate Program in Health Science, Federal University of Rio Grande do Norte, ${ }^{\prime}$ Natal, RN - Brazil State University of Rio Grande do Norte, ${ }^{2}$ Mossoró, RN - Brazil

Department of Physical Education, Federal University of Rio Grande do Norte, ${ }^{3} \mathrm{Natal}, \mathrm{RN}$ - Brazil

Biotechnology Graduate Program, University Potiguar, ${ }^{4}$ Natal, RN - Brazil

\section{Background}

The recent outbreak of coronavirus disease (COVID-19) is considered a global health emergency. The global impact of this viral infection is of great concern to everyone. ${ }^{1}$ As the COVID-19 outbreak continues to appear unstoppable, preventive and hygiene measures have been implemented to safeguard against infection. Among these precautions, social isolation is considered to have the greatest potential for reducing contagion, at least until a vaccine becomes available. This isolation measure works as a kind of "necessary evil" for preventing a widereaching disaster. Thus, social distancing and staying home remain the most effective restrictive measures to prevent the exponential increase in contagion. ${ }^{2}$

One of the crucial focal points of this strategy was oriented toward the closure of schools, thus affecting thousands of children and adolescents, who comprise approximately half of the global student population. The closure of educational institutions could have a significant impact on their lives, requiring them to adapt to new routines. Considering that they are now being confined to their homes due to the new situation generated by the pandemic, this cohort may experience moments of stress. ${ }^{3}$

Studies reveal that the lack of social interaction can lead to the development of various symptoms of anxiety

\section{Keywords}

COVID-19; Betacoronavirus, Pandemics; Child; Adolescent; Students; Sports; Exercises; Schools Closure; Social Isolation; Physical Activity. and depression, and consequently, to the development of mental illnesses and an inevitable increase in stress. ${ }^{4}$ Additionally, a study suggests that the proportion of patients with obesity will increase during the COVID-19 pandemic. This raises additional medical concerns because obesity is linked to decreased immune function, which could in turn increase viral pathogenicity. ${ }^{5}$ In this context, there is a continued need for developing improved communication strategies to provide the general population with actionable information for selfprotection, including the identification of symptoms, and clear guidelines for seeking supporting treatments. ${ }^{6}$ Evidently, such programs must adopt behavioral elements, and they should be feasible to implement for individuals who face changes in schedules, work, and school requirements. This is especially true for those who experience anxiety owing to being confined to their home. Additionally, sedentary behaviors of children and adolescents, who tend to resort to screen-based leisure activities (using tablets/smartphones, TV games/videos/ DVDs, and computers/laptops), should be addressed.?

Given these factors, intervention programs that include physical activity could minimize anxiety and stress, and they could play an important role in preventing weight gain, dyslipidemia, and cardiovascular events. ${ }^{8,9}$ The importance of physical exercise is well evidenced in the literature; however, under conditions of social isolation, children and adolescents cannot exercise in other spaces with face-to-face guidance from a qualified professional (e.g., at the school, club, or gym). However, it is relevant to mention that home-based training programs and exercise routines could also be effective for children and 
adolescents, ${ }^{9}$ as it increases levels of physical activity, and consequently, improves the quality of life of those involved.

In recent years, the literature has increasingly addressed the effectiveness of physical exercise as a therapeutic and preventive measure against mental and physical disorders. ${ }^{5,10}$ It is a great way of maintaining and caring for the physical body. At a chemical level, it increases serotonin synthesis and activates the endogenous opioid system (endorphin synthesis), which, along with other benefits, results in a decrease in sensitivity to anxiety and amplifies positive emotions. ${ }^{11}$

In the context of the COVID-19 pandemic and in the absence of studies on possible strategies to increase physical activity in children and adolescents, these discussions are imperative. ${ }^{12,13}$ Until new discoveries emerge, we must emphasize that modifiable lifestyle factors, such as diet and physical activity, should not be marginalized because decades of evidence corroborate the role of physical activity in promoting health and well-being. In times of crisis, whether real or perceived, the benefits of enabling people to actively preserve their own health, for example by performing exercises at home, cannot be discounted. ${ }^{14}$

Thus, to address the relationship between children's and adolescents' general health and physical exercise at home, this study sought to answer the following question: Which evidence-based exercise programs can be implemented at home for children and adolescents during this period of social isolation related to the COVID-19 pandemic?

\section{General Guidelines on Physical Activities for Children and Adolescents}

The guidelines of the World Health Organization (WHO) on physical activities for children and adolescents
(5-17 years) recommend at least 60 minutes of daily physical activity of moderate to vigorous intensity (e.g., which lead to an increase in heart rate). Some recommended activities include games, sports, taskbased online games, recreation, physical education, or planned exercise, which are conducted in the context of the family, school, and community activities. ${ }^{15}$

With the spread of COVID-19, some recommendations have been modified to facilitate the implementation of protective measures against the infection and to help individuals during social isolation. These modifications mainly pertain to spaces where these recommendations are implemented. For instance, it is recommended that children and adolescents remain active or begin to engage in physical activities at home, together with their families. ${ }^{16}$ Some of these activities, such as a resistancebased exercise program, games, dance, sports activities, and task-based online games, should be encouraged for children and adolescents (Figure 1).

Games and play offer children with opportunities to receive diverse experiences and achieve new stages in their learning. Playing, a typical childhood activity, paves the way for children to be more assertive and provides constant opportunities to interact with other individuals and cultures. This, in turn, facilitates the collective construction of knowledge. Thus, games and play are relevant, educational, and ludic activities that can be performed at home. ${ }^{17}$ Aerobic exercises that can be performed to improve cardiorespiratory fitness include jumping rope, going up and down stairs, walking, stationary or treadmill running, cycling, performing cyclical or repetitive movements, and dancing. Resistance exercises, which improve strength, power, and muscular

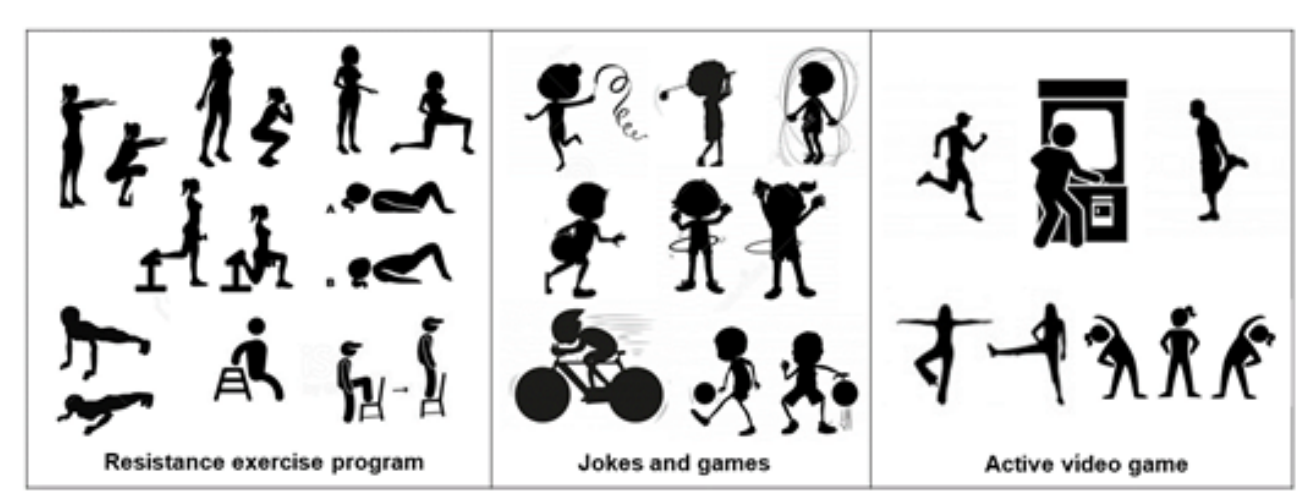

Figure 1 - Different physical activities to be performed at home by children and adolescents 
endurance, can be performed by children and adolescents by using their own body weight for creating resistance. Plyometric or jump exercises, such as burpees, jump squats, and jumping jacks, are recommended for bone strengthening. These exercises can be performed alone or in combination with other exercises at home. ${ }^{5,18,19}$

Additionally, recommended physical activities include active games associated with video games, applications, or software. Such activities were developed in response to the increase in the number of hours children and adolescents spend on sedentary activities such as watching television, using their cell phones, and playing video games. To counter this sedentary behavior trend, studies have started testing the use of technology to remedy this sedentary lifestyle while encouraging children to continue to play. Active video games (AVGs) emerged with the need to encourage movement through interaction with technology. Such games encourage physical activity of mild to moderate intensity while motivating children and adolescents to increase their energy expenditure. ${ }^{19}$
Evidently, AVGs could be an essential tool during this period of social isolation.

A study that sought to test the effectiveness of a home-based physical activity intervention led by parents of young individuals (age $<18$ years old) found that the intervention led to improvements in motor skills such as upper-limb coordination, bilateral coordination, balance, running speed, agility, and muscle strength. Thus, it is indicated that such tools could facilitate the implementation of physical activity routines that improve motor proficiency in young individuals. ${ }^{20}$ Table 1 shows some activities that can be conducted at home, with suggestions that incorporate readily available household materials and simple movements that can be practiced by children and adolescents during this period of social isolation.

\section{Conclusion}

Home-based exercise programs for children and adolescents include resistance-based exercises or muscle-

Table 1 - Examples of programs of physical activity at home.

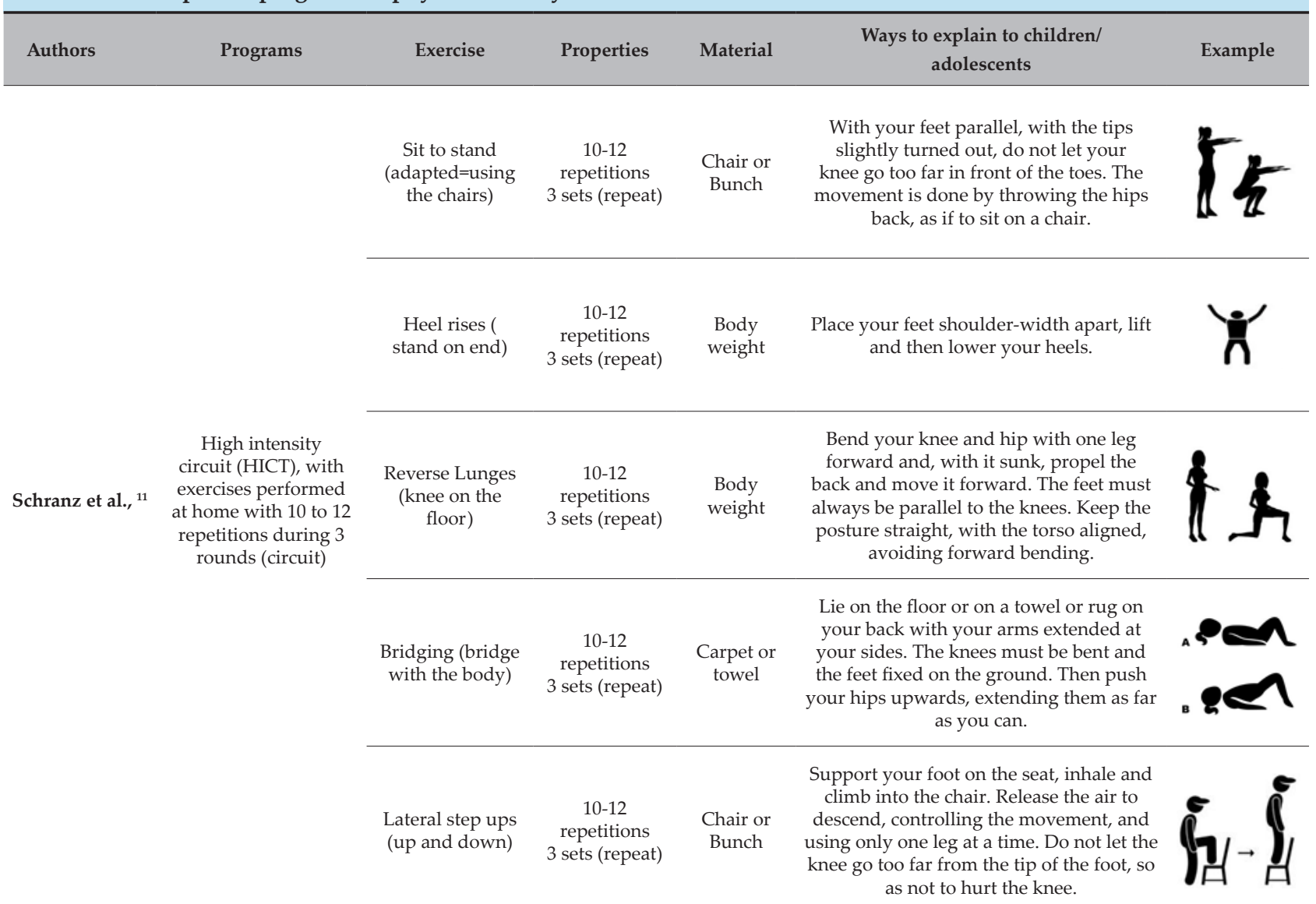




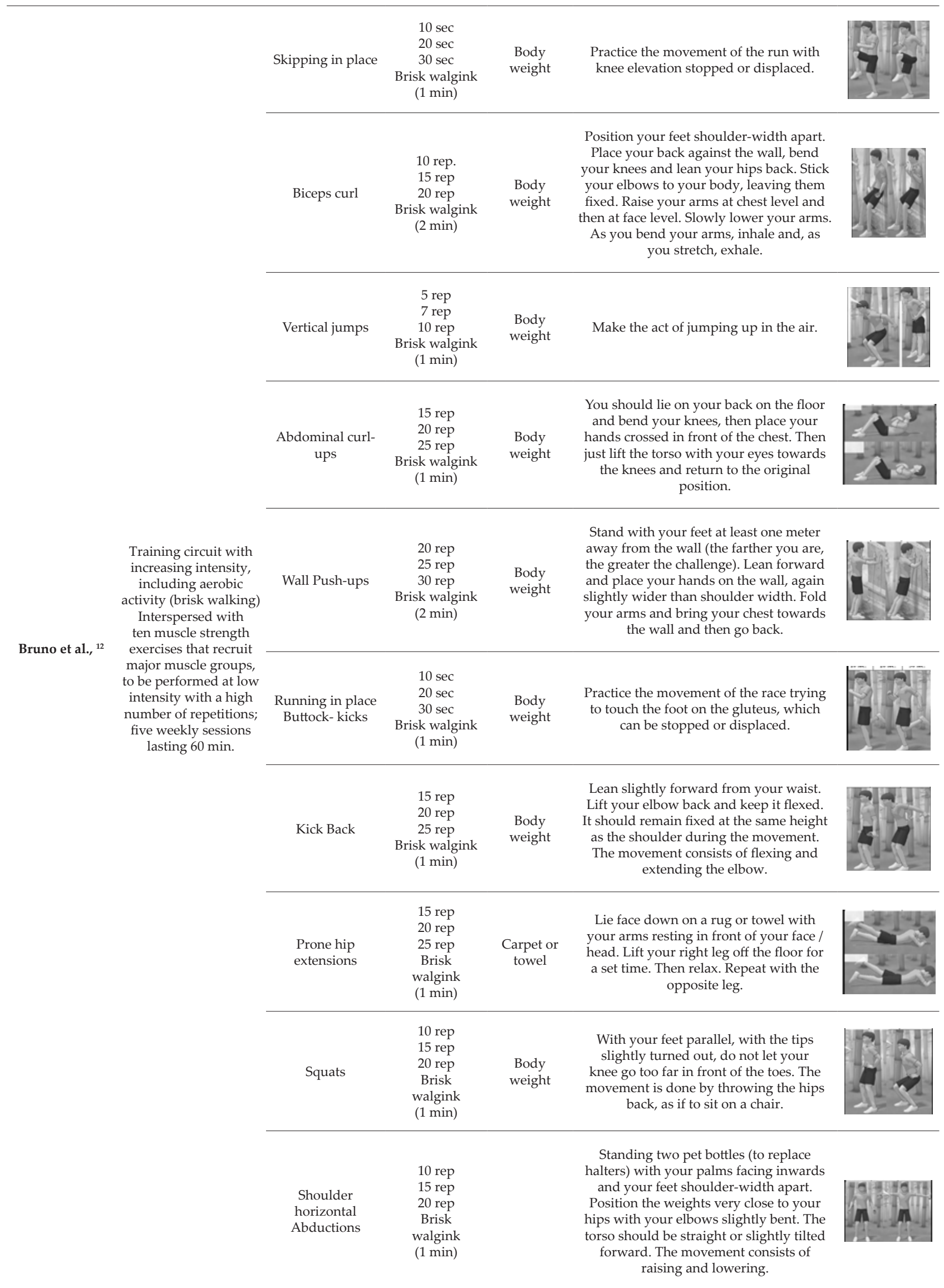


strengthening activities, games, dance (aerobic exercises), sports activities, and task-based online games (for bone strengthening). These exercises will enable them to remain active.

Children and adolescents should be encouraged to change their routines during this period of social isolation. A reasonable goal could be to engage in 60 minutes or more of moderate and/or vigorous intensity activities each day.

Further, it is important to engage in such activities under the supervision of parents or guardians since they play an important role in providing age-appropriate activities for children and adolescents. It is also noteworthy that adolescents usually tend to reduce their levels of physical activity. Accordingly, it is important for parents to motivate them to initiate and maintain good physical exercise habits that contribute to an increase in energy expenditure during the COVID-19-related quarantine period.

This review points out that children and adolescents could engage in moderate-intensity physical activity with AVGs and task-based online games. Such homebased activities could improve their self-esteem, facilitate positive family interactions, and maintain physical activity during social isolation.

\section{Acknowledgments}

Acknowledgments to the Higher Education Personnel Improvement Coordination - Brazil (CAPES), to the
Postgraduate Program in Health Science and Federal University of Rio Grande do Norte.

\section{Author Contributions}

Conception and design of the research: Medeiros RCSC, Santos IK, Medeiros JA, Cobucci RN, Silva TAL, Araujo JS, Varela PWA, Cabral BGAT, Dantas PMS. Acquisition of data: Medeiros RCSC, Santos IK, Medeiros JA, Cobucci RN, Silva TAL, Araujo JS, Varela PWA, Cabral BGAT, Dantas PMS. Analysis and interpretation of the data: Medeiros RCSC, Santos IK, Medeiros JA, Cobucci RN, Silva TAL, Araujo JS, Varela PWA, Cabral BGAT, Dantas PMS. Writing of the manuscript: Medeiros RCSC, Santos IK, Medeiros JA, Cobucci RN, Silva TAL, Araujo JS. Critical revision of the manuscript for intellectual content: Medeiros RCSC, Santos IK, Medeiros JA, Cobucci RN, Silva TAL, Araujo JS, Varela PWA, Cabral BGAT, Dantas PMS.

\section{Potential Conflict of Interest}

No potential conflict of interest relevant to this article was reported.

\section{Sources of Funding}

There were no external funding sources for this study.

\section{Study Association}

This study is not associated with any thesis or dissertation work.

\section{References}

1. Sohrabi C, Alsafi Z, O'Neill N, Khan M, Kerwan A, Al-Jabir A, et al. World Health Organization declares global emergency: a review of the 2019 novel coronavirus (COVID-19). Int J Surg. 2020 Apr;76:71-6.

2. Lippi G, Henry BM, Bovo C, Sanchis-Gomar F. Health risks and potential remedies during prolonged lockdowns for coronavirus disease 2019 (COVID-19). Diagnosis. 2020;7(2):85-90.

3. Brooks SK, Webster RK, Smith LE, Woodland S, Wessely S, Greenberg $\mathrm{N}$, et al. The psychological impact of quarantine and how to reduce it: rapid review of the evidence. Lancet. 2020;395(10227):912-20.

4. Uchino BN, Cronan S, Scott E, Landvatter J, Papadakis M. Social support and stress, depression, and cardiovascular disease. New York: Academic Press; 2020. Chapter 9, Cardiovascular implications of stress and depression; p. 211-23.

5. CarterSJ, Baranauskas MN, Fly AD. Considerations for obesity, vitamin D, and physical activity amidst the COVID-19 pandemic. Obesity. 2020;28(7):1176-7.

6. Eddolls WT, McNarry MA, Stratton G, Winn CON, Mackintosh KA. High-intensity interval training interventions in children and adolescents: a systematic review. Sports Med. 2017;47(11):2363-74.

7. Altena E, Baglioni C, Espie CA, Ellis J, Gavrioff D, Holzinger B, et al. Dealing with sleep problems during home confinement due to the COVID-19 outbreak: practical recommendations from a task force of the European CBT-I Academy. J Sleep Res. 2020;29(4):e13052.

8. Dietz, W, Santos-Burgoa C. Obesity and its implications for COVID-19 mortality. Obesity. 2020;28(6):1005.

9. Reuter CP, Brand C, Silva PT, Reuter EM, Renner JDP, Franke SIR, et al. Relationship between dyslipidemia, cultural factors, and cardiorespiratory fitness in schoolchildren. Arq Bras Cardiol. 2020;112(6):729-36.

10. Anderson EH, Shivakumar G. Effects of exercise and physical activity on anxiety. Front Psychiatry. 2013 Apr 23;4:27.

11. Schranz C, Kruse A, Belohlavek T, Steinwender G, Tilp M, Pieber T, et al. Does home-based progressive resistance or high-intensity circuit training improve strength, function, activity or participation in children with cerebral palsy? Arch Phys Med Rehabil. 2018;99(12):2457-64.e4. 
12. Bruñó A, Escobar P, Cebolla A, Alvarez-Pitti J, Guixeres J, Lurbe E, et al. Home-exercise childhood obesity intervention: a randomized clinical trial comparing print versus web-based (Move It) platforms. J Pediatr Nurs. 2018;42:e79-84

13. Jiménez-Pavón D, Carbonell-Baeza A, Lavie CJ. Physical exercise as therapy to fight against the mental and physical consequences of COVID-19 quarantine: special focus in older people. Prog Cardiovasc Dis. 2020;63(3):386-8

14. Maher JP, Doerksen SE, Elavsky S, Hyde AL, Pincus AL, Ram N, et al. A daily analysis of physical activity and satisfaction with life in emerging adults. Health Psychol. 2013;32(6):647-56.

15. World Health Organization. Global recommendations on physical activity for health. Geneva: WHO; 2010.

16. World Health Organization. Advice on the use of masks in the community, during home care and in health care settings in the context of the novel coronavirus (2019-nCoV) outbreak: interim guidance. Geneva: WHO; 2010

17. Rodrigues PLM, Iwamoto V, Campos MI. Jogos e brincadeiras: possibilidades no centro social marista de Dourados/MS. Cad Pedagogia. 2019;12(23):81-95.

18. Gómez-Bruton A, Matute-Llorente Á, González-Agüero A, Casajusez JA, Vicente-Rocrigues G. Plyometric exercise and bone health in children and adolescents: a systematic review. World J Pediatr. 2017;13(2):112-21.

19. Liang Y, Lau PWC. Effects of active videogames on physical activity and related outcomes among healthy children: a systematic review. Games Health J. 2014;3(3):122-44.

20. Rubin DA, Wilson KS, Dumont-Driscoll M, Rose DJ. Effectiveness of a parent-led physical activity intervention in youth with obesity. Med Sci Sports Exerc. 2019;51(4):805-13. 